\title{
Pearl Millet Blast Pathogen Virulence Study and Identification of Resistance Donors on Virulent Isolate
}

\author{
K. Bramareswara Rao' ${ }^{1}$ S.R. Krishna Motukuri' ${ }^{1 *}$, K. Arun Kumar², \\ CHVN Praveen Babu² and Vaibhav Pathak ${ }^{2}$ \\ ${ }^{1}$ Department of Biotechnology, Koneru Lakshmaiah Education Foundtion, Guntur - 522 502, \\ Andhra Pradesh, India. \\ ${ }^{2}$ Department of Crop Improvement, Rasi Seeds Pvt Ltd, Toopran, Hyderabad - 502 334, Telangana, India.
}

\begin{abstract}
Pearl Millet leaf Blast caused by Pyricularia grisea [teleomorph: Magnaporthe grisea], is spreading at an alarming rate in the major Pearl millet growing geographies of India effecting grain yield and green fodder yield. Blast isolates collected from Jaipur, Alwar and Toopran regions of India and virulence study conducted to identify the most virulent isolate among the three isolates. Artificial screening for Blast conducted on a raised bed method utilising uniform Blast Nursery (UBN) method. Eleven Pearl Millet genotypes (ICMB01333, ICMB03444, ICMB03555, ICMB06111, ICMB95444, ICMB11666, ICMB14333, ICMB14666, ICMB97111, ICMR12888 and ICMR06444) were screened with three blast isolates utilising artificial screening method. Among the eleven genotypes, ten genotypes were showing susceptible to Jaipur isolate indicating that the Jaipur isolate having highest virulence among the three isolates. To identify Blast resistant donors for Jaipur isolate, a set of $\mathbf{9 3}$ genotypes containing of $\mathbf{4 5}$ maintainer lines and 48 restorer lines were screened under both UBN and field conditions (Jaipur, Rajasthan). Among all the lines evaluated, five lines are showing resistant reaction for Jaipur isolate with disease score less than 1.9. ICMR06444 from restorer background and IC414K14B5, IC594K16B5, RBB037 and IC6912K18B from maintainer background are identified as resistant lines. Identified lines can be utilised in pearl millet hybrid breeding programme.
\end{abstract}

Keywords: Pearl Millet, Blast, Screening, Restorer, Maintainer, Resistance

\footnotetext{
*Correspondence: msrkrishna_bt@kluniversity.in

(Received: September 9, 2020; accepted: April 3, 2021)

Citation: Rao KB, Motukuri SRK, Kumar KA, Babu CHVNP, Pathak V. Pearl Millet Blast Pathogen Virulence Study and Identification of Resistance Donors on Virulent Isolate. J Pure App/ Microbiol. 2021;15(2):752-758. doi: 10.22207/JPAM.15.2.27

(C) The Author(s) 2021. Open Access. This article is distributed under the terms of the Creative Commons Attribution 4.0 International License which permits unrestricted use, sharing, distribution, and reproduction in any medium, provided you give appropriate credit to the original author(s) and the source, provide a link to the Creative Commons license, and indicate if changes were made.
} 


\section{INTRODUCTION}

Pearl millet (Pennisetum glaucum (L.) R. Br., syn. Cenchrus americanus (L.) Morrone), a C4 grass, is a highly cross-pollinated diploid crop ( $2 n$ $=2 x=14)$. Pearl millet accounts for more than half of the total millet production in the world ${ }^{12}$. Pearl millet majorly grown as a rainfed crop ${ }^{5}$ is considered as a climate resilient and hardy crop due to its ability to sustain in most harsh environments like erratic and scarce rainfall, high temperature, less fertile soils where other cereals like Maize and Wheat cannot be cultivated ${ }^{10}$. India is the largest producer of pearl millet in the world 3 which is cultivated in both rainy and summer seasons in North-Western parts of India'. Among the states cultivating Pearl Millet, Rajasthan has the largest area under cultivation ${ }^{1}$ followed by Maharashtra, Haryana, Gujarat, and Uttar Pradesh. Owing to the consistent efforts of researchers over the years to develop resistant cultivars against downy mildew, pearl millet cultivars are showing significant tolerance to Downy Mildew which lead to protection of the crop yields ${ }^{14}$. In India pearl millet leaf blast disease was reported initially in $1953^{4}$ and after that it is sporadically reported on some of the cultivars. Since the year 2000 the leaf blast is becoming more serious and is now gaining increasing importance due to its high and widespread incidence across the pearl millet cultivating states in India ${ }^{5}$ and other Pearl Millet growing geographies?

Blast disease is caused by fungal organism Magnaporthe grisea (T.T. Hebert) M.E. Barr. Hot humid weather especially during rainy days is the most conducive conditions for the pathogen to grow and spread. Disease severity survey conducted by All India Coordinated Pearl Millet Improvement Project in the farmers field for the years 2016-2018 is showing alarming trend of disease incidence that has reached up to 60 to $90 \%$ across various pearl millet growing states ${ }^{2}$. Sharma et $\mathrm{al}^{7}$ reported 25 pathotypes of blast across various states in India, viz., Maharashtra, Haryana, Rajasthan, Uttar Pradesh, and Andhra Pradesh. Pearl millet is majorly grown by resource poor farmers so, growing of resistant cultivars is the best way to overcome yield losses caused by $M$. grisea. Pearl millet researchers and institutions like International Crops Research Institute for the Semi-Arid Tropics (ICRISAT) working on identifying resistant donors and the genes conferring resistance. Developing varieties and hybrids with host plant resistance 8 is the forward way to control this disease and reduce the loss of grain yield and forage quality. In the present study, to identify the most virulent blast isolate for the screening of pearl millet germplasm lines.

\section{MATERIALS AND METHODS \\ Survey and Isolates Collection}

Farmer's fields of Pearl Millet crop were surveyed during the years 2018 and 2019 in Jaipur and Alwar locations where Pearl Millet is grown predominately in Kharif. Blast isolates are collected from three locations viz.,1. Akedachoda, Jaipur, 2. Malakheda, Alwar and 3. Toopran, Hyderabad, Telangana. The diseased leaves were surface sterilized by using $70 \%$ ethanol and rinsed thrice with sterile distilled water. The leaf bits were placed on the oatmeal agar media and the isolates are purified by single spore technique ${ }^{18}$.

Inoculum Multiplication and inoculation

The isolates were multiplied in modified Baite Agar media ${ }^{19}$. The plates are streaked with fungal inoculum and incubated at $28^{\circ} \mathrm{C}$ for 7 days. After 7 days the conidia are harvested with sterile distilled water and conidial solution is prepared by adjusting the spore concentration as $10^{5}$ conidia/ml of water with two drops of Tween 20 as adhesive agent.

\section{Host Differential study}

A set of eleven germplasm lines are collected from ICRISAT under the Hybrid Parents Research Consortia (HPRC). The collected lines are sown in Uniform Blast Nursery (UBN) by adapting the technique of screening which was employed by International Rice Research Institute (IRRI) for identifying the blast resistance donors from large pool of rice germplasm ${ }^{15}$.

The seeds are sown on raised nursery bed with a spacing of $10 \mathrm{~cm}$ (Genotype to Genotype), the plants population is maintained uniformly by keeping 20 plants/test lines and thinning out the excess seedling after 10 days of sowing. Fertilizers are applied as basal dose at the time of nursery bed preparation.

Twenty days old plants with four to five leaves stage were inoculated in the evening after $5 \mathrm{pm}$ by spraying conidial suspension. The nursery bed is covered by plastic sheets (Fig.1) immediately 
after inoculation to maintain high humidity. During the daytime, the water is misted to maintain optimum temperature $\left(26-27^{\circ} \mathrm{C}\right)$ and the plants were covered with plastic sheets in the night to ensure the relative humidity $(90 \%)$ is maintained for spore germination and infection. The blast score taken after 14 days from inoculation by the scale given by ICRISAT ${ }^{20}$.

\section{Disease severity Score and Scale Highly resistant}

Score 1= no lesion to small brown specks of pinhead size

\section{Resistant}

Score 2= large brown specks, Score $3=$ small, roundish to slightly elongated, necrotic gray spots, about 1-2 $\mathrm{mm}$ in diameter with a brown margin

\section{Moderately Resistant}

Score 4= typical blast lesions, elliptical, 1-2 cm long, usually confined to the area between main veins, covering $<2 \%$ of the leaf area, Score $5=$ typical blast lesions covering $<10 \%$ of the leaf area

\section{Susceptible}

Score 6=typical blast lesions covering 10$25 \%$ of the leaf area Susceptible, score $7=$ typical blast lesions covering $26-50 \%$ of the leaf area Highly susceptible

Score 8=typical blast lesions covering 51$75 \%$ of the leaf area and many leaves dead.

Score $9=>75 \%$ leaf area covered with lesions and most leaves dead. Disease development is growth-stage dependent (Wilson and Hanna 1992).

Evaluation of Germplasm

Artificial Screening

A set of 93 germplasm lines which are agronomically superior (45 maintainer lines and 48 restorer lines) are sourced from International Crop Research Institute for Semi-Arid Tropics (ICRISAT) and RASI Seeds (P) Ltd and are further screened with the Jaipur isolate utilising UBN methodology with four replications in Randomised block design. Susceptible checks are planted on all the borders and after every fifth test entry to increase the load of spores for disease infection. Artificial inoculation is done by spraying the conidial suspension on the seedlings at the stage of twenty days old in the evening hours and is continued for a week. The Blast score is collected on all genotypes after 14 days from inoculation by the scale given by ICRISAT Hotspot screening under field conditions

The same set of lines evaluated in artificial screening i.e 45 maintainer lines and 48 restorer lines are also evaluated in the field screening experiment for identifying the resistance against Pearl Millet blast. Field screening is conducted at Akheda Chaud, Jaipur, Rajasthan with 3 replications. These lines are sown in ridges and furrows with a row to row distance of $40 \mathrm{~cm}$ and plant to plant distance of $15 \mathrm{~cm}$. The susceptible checks are sown after every five genotypes and all borders to ensure the uniform disease incidence and spread. Sprinklers are used to maintain optimum conditions for temperature and moisture conditions for the development of disease incidence.

\section{RESULTS}

\section{Host Differential study}

A set of eleven Genotypes were screened for blast susceptibility against three isolates 1 . Akedachoda, Jaipur, 2. Malakheda, Alwar and 3. Toopran, Hyderabad, Telangana. Genotype ICM95444B (Fig:2) used as a check has developed severe disease spots on leaves against all three isolates and categorised as highly susceptible based on the disease score. Blast scores are collected from eleven genotypes (Table1) including check. Jaipur isolate has mean blast score of 6.91 followed by Toopran isolate 6.28 and Alwar isolate 5.94 respectively. Among the three isolates, Jaipur isolate is showing high mean blast severity score of 6.91 across the eleven differential lines. This indicates that the Jaipur isolate is showing highest virulence.

Genotype ICMR06444 (Fig:3) disease scores are recorded as 1.9 on both Jaipur and Toopran isolates and 2.6 on Alwar isolate. ICMR06444 found resistant across all the three pathotypes, which indicates the stability of resistance across the pathotypes. This genotype can be used as a resistance donor in developing multi pathotype resistant restorer Lines. Genotypes ICMB03444, ICMB11666 and ICMB14666 are found moderate resistant to Alwar and Toopran isolates, but susceptible to Jaipur isolates which leads the way to take up pre-breeding activities to pyramid the resistant source in the said three lines. 


\section{Germplasm Evaluation}

A set of 93 genotypes which includes 45 maintainer lines and 48 restorer lines are screened against three isolates by Uniform Blast Nursery (UBN) in artificial screening conditions and field conditions in Jaipur. Resistant line ICMB95444 had mean disease score of 7.94 in the artificial screening across the three pathotypes and 8.6 in the field screening at Jaipur indicating that ICMB95444 is susceptible for blast. Among all the Genotypes IC414K14B5, IC594K16B5, IC6912K18B, RBB037, ICMR06444, TS19K461 are found with low mean severity scores (Table 2 ).
Genotype IC36844K18R shows low blast score (2.35) in hotspot, compared to artificial screening (4.9). Ten Genotypes Viz., IC16576K16R, IC15354K18R, IC16714K18R, IC16752K18R, IC16975K18R, IC17002K18R, IC17057K18R, IC17137K18R, IC25251R18R, IC25254R18R are found resistant to Jaipur isolates in UBN but slightly the resistant levels are low in Hotspots.

\section{DISCUSSION}

The host plant resistance varies with different pathogenic strains of the same pathogen, it is well defined in cereal pathology with

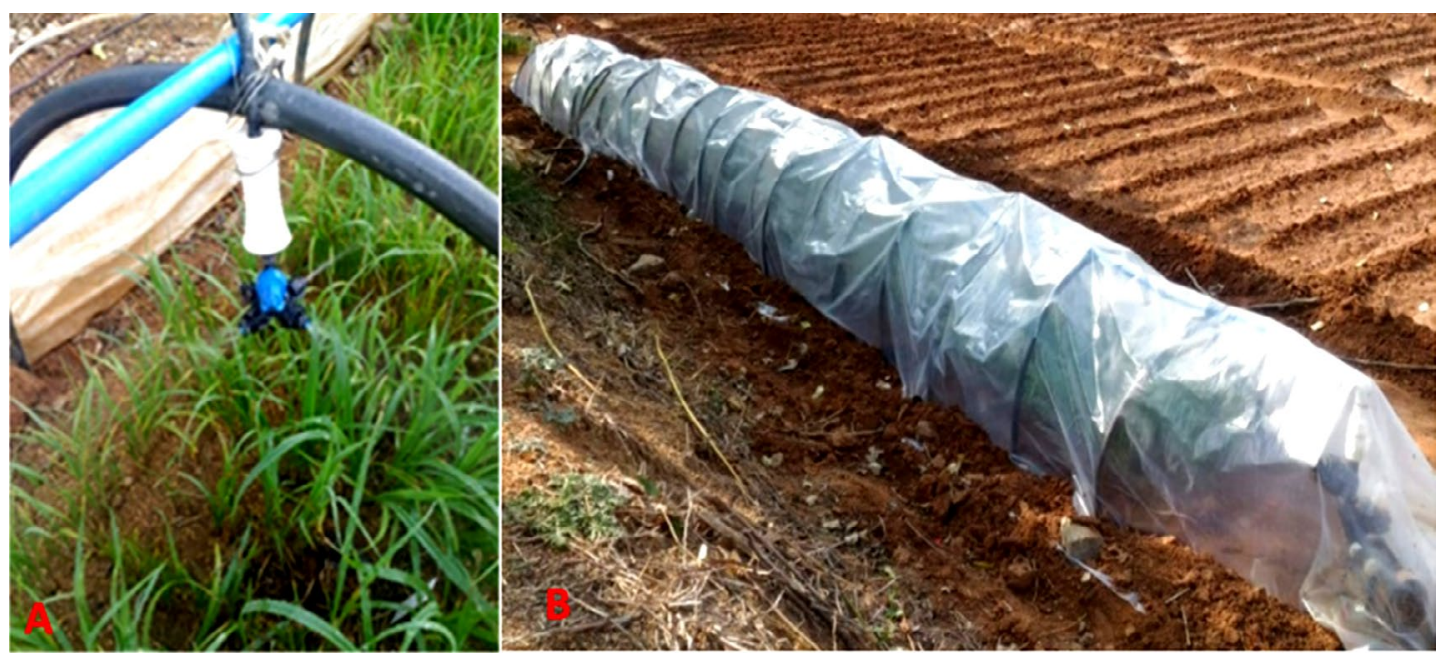

Fig. 1. Uniform Blast Nursery Raised Seed Bed A) Sprinkler for humidity B) Raised Bed covered with plastic sheets

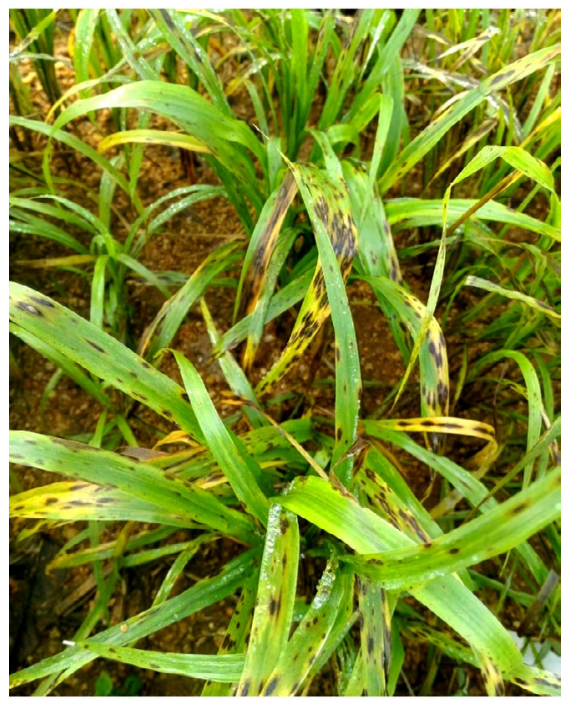

Fig. 2. Susceptible check plant with Blast spots

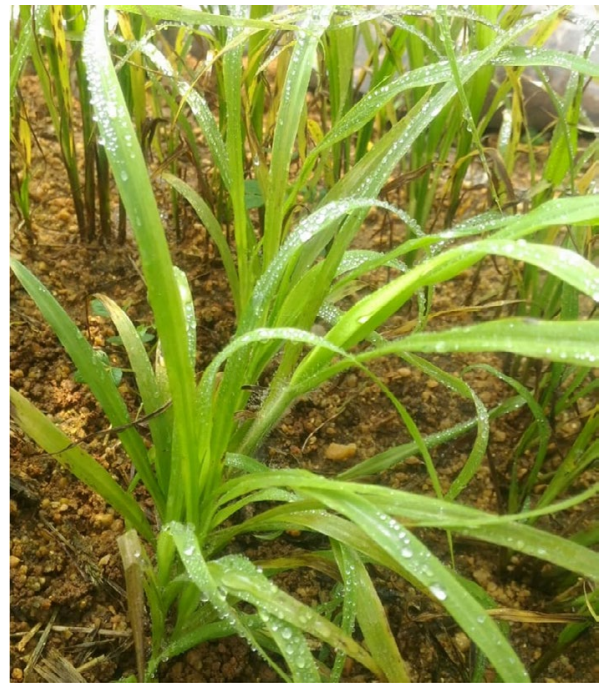

Fig. 3. Resistant plants without disease spots

Journal of Pure and Applied Microbiology 


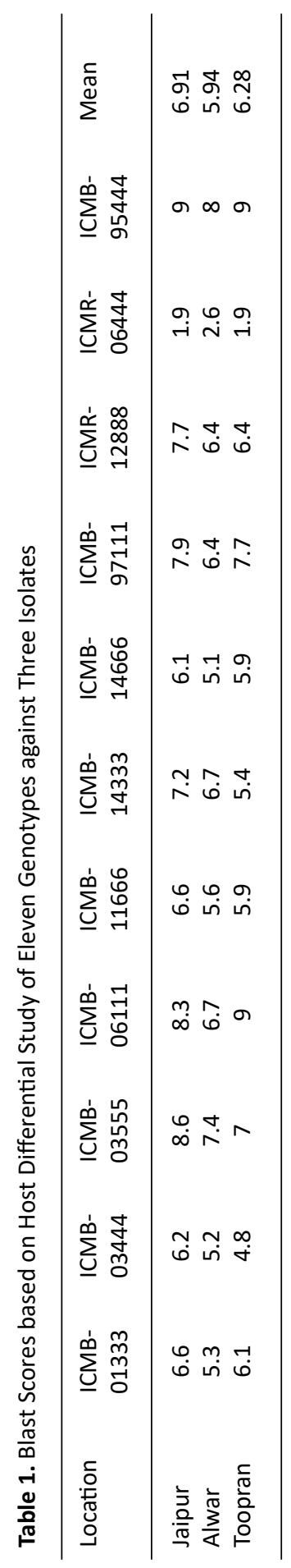

respective to rust, mildew and other diseases caused by fungal pathogens ${ }^{17}$. The pearl millet blast pathogen is highly diverse in nature, which needs rigorous screening to understand the genes responsible for the host resistance ${ }^{11}$. To simplify and to use the resources efficiently we made an attempt to screen the pearl millet genotypes utilising artificial screening namely Uniform Blast Nursery (UBN) which is a proven method to screen rice genotypes for Blast disease ${ }^{15}$. The results shown clear difference between the susceptible, moderately resistant, and resistant genotypes. It gives the opportunity to screen the germplasm and to find out the resistant source within a short period.

The host differential study results are similar to the findings by Sharma et al. Most virulent isolate Pg118 was isolated from Rewari, Haryana ${ }^{7}$. In the present study Jaipur isolate shown highest virulent on all the genotypes except the genotype ICMR0644 was found to be resistant across the pathotypes. The results revealed that three isolates showing different reaction pattern on the eleven host differentials. The Genotype IC414K14B5, IC594K16B5, IC6912K18B, RBB037, ICMR06444 and TS19K461 found to be low mean severity scores which indicates their resistant level, in which IC414K14B5, IC594K16B5, IC6912K18B, RBB037 are having maintainer ability and ICMR06444 and TS19K461 have restorer ability which will be highly useful in developing the Pearl millet hybrids. Genotype IC36844K18R was resistant to hotspot, but in artificial screening Jaipur isolate was shown reaction towards moderate resistant reaction which gives an evidence that adult plant may show better resistant than seedling level which depends on the genotype.

Ten genotypes viz., IC16576K16R, IC15354K18R, IC16714K18R, IC16752K18R, IC16975K18R, IC17002K18R, IC17057K18R, IC17137K18R, IC25251R18R, IC25254R18R are found resistant to Jaipur isolates in UBN, but they are showing variable resistance reaction with other two isolates. In the present study observed that Thirty-two accessions selected from the mini-core were not shown resistant to all five pathotypes; however, resistance to any four pathotypes was observed in IP 7846, IP 11036, and IP 21187. These results were correlated with Sharma et $\mathrm{al}^{8}$. 
Table 2. Resistant Genotype Blast Scores in UBN and Field Condition

\begin{tabular}{lccccccc}
\hline Group & $\begin{array}{c}\text { Genotype } \\
\text { Name }\end{array}$ & $\begin{array}{c}\text { Blast } \\
\text { Score } \\
\text { Jaipur } \\
\text { Isolate }\end{array}$ & $\begin{array}{c}\text { Blast } \\
\text { Score } \\
\text { Alwar } \\
\text { Isolate } \\
\text { Uniform Blast }\end{array}$ & $\begin{array}{c}\text { Blast } \\
\text { Score } \\
\text { Toopran } \\
\text { Isolate }\end{array}$ & $\begin{array}{c}\text { Mean } \\
\text { score }\end{array}$ & $\begin{array}{c}\text { Jaipur } \\
\text { Field } \\
\text { Score }\end{array}$ & $\begin{array}{c}\text { Disease } \\
\text { Scale }\end{array}$ \\
\hline Maintainer & IC414K14B5 Score & 1.77 & 1.36 & 2.6 & 1.91 & 1.82 & Highly Resistant \\
Maintainer & IC594K16B5 & 2.8 & 1.84 & 1.52 & 2.05 & 1.85 & Highly Resistant \\
Maintainer & IC6912K18B & 2.68 & 1.36 & 1.57 & 1.87 & 1.85 & Highly Resistant \\
Maintainer & RBB037 & 1.65 & 1.77 & 1.16 & 1.52 & 1.65 & Highly Resistant \\
Restorer & ICMR06444 & 2.57 & 2.29 & 1.39 & 2.08 & 1.9 & Highly Resistant \\
Restorer & TS19K461 & 2.51 & 2.66 & 2.54 & 2.57 & 2.2 & Resistant \\
\hline
\end{tabular}

In the present study reveals that the potential of pearl millet blast infection, disease spreading and destroying the crop. Symptoms of the disease will initiate with small spots on margins or tip of leaves or stem which are called as grey spots. These spots gradually broaden and coalesce to form a necrotic regions or blast appearance ${ }^{13}$. Due to these symptoms on leaf and stem there is a significant reduction in grain yield6 and quality of the fodder ${ }^{16}$.

Based on this study the blast resistant donors were identified in both maintainer and restorer genetic background which will be highly useful in designing the pearl millet breeding program. This study can be useful for the mapping of genes which confers resistant to pathogen. It will be the prime focus in the future Peral millet breeding programs. Identification of blast resistance lines in the existing germplasm and confirming the resistance in the disease hot spot area will be the way out certainly to aid in breeding of tolerant lines. Among the 93 germplasm lines evaluated in screening, thirty-four lines are moderately resistant, forty-six lines are moderately susceptible, seven lines are susceptible, and six lines are resistant. These resistant lines can be used as good source for pearl millet blast resistance breeding programme.

\section{ACKNOWLEDGMENTS}

Authors would like to thank the HOD, Department of Biotechnology KL University, and Management, Rasi Seeds (P) Ltd for conducting the Experiment and analyzing the data.

\section{CONFLICT OF INTEREST}

The authors declare that there is no conflict of interest.

\section{AUTHORS' CONTRIBUTION}

All authors listed have made a substantial, direct, and intellectual contribution to the work, and approved it for publication.

\section{FUNDING}

None

\section{DATA AVAILABILITY}

All datasets generated or analyzed during this study are included in the manuscript.

\section{ETHICS STATEMENT}

This article does not contain any studies with human participants or animals performed by any of the authors.

\section{REFERENCES}

1. Munasib A, Devesh R, Ekin B. Networks and low adoption of hybrid technology: The case of pearl millet in Rajasthan, India. Washington, D.C.: International Food Policy Research Institute (IFPRI). HarvestPlus, 2015; 19. http://ebrary.ifpri.org/cdm/ref/collection/ p15738coll2/id/129796C

2. Tara SC. Annual Report: All India Coordinated Research Project on Pearl Millet (Indian Council of Agricultural Research), Mandor, Jodhpur - 342 304, Chapter-IV. Plant pathology. 2:2016-17:1-87. http://www.aicpmip. res.in/ar2017.pdf

3. Basavaraj G, Parthasarathy RP, Bhagavatula S, Ahmed $W$. Availability and utilization of pearl millet in India. Journal of SAT Agricultural Research. 2010; 8.

4. Chandra NS, Srivastava RK, Udayashankar AC, Lavanya SN, Prakash G, Bishnoi HR, DL Kadvani, Om 
VS, Niranjana SR, Prakash HS, and Tara Satyavathi C. Magnaporthe. Blast of Pearl Millet in India - Present status and future prospects.. 2017; 1-51. http://www. aicpmip.res.in/Magnaporthe_Blast_of_Pearlmillet_ in_India.pdf

5. Yadav OP, Rai KN. Genetic Improvement of Pearl Millet in India. Agricultural Research. 2013;275-292. doi: 10.1007/s40003-013-0089-z

6. Timper P, Wilson JP, Johnson AW, Hanna WW. Evaluation of Pearl Millet Grain Hybrids for Resistance to Meloidogyne spp. and Leaf Blight Caused by Pyricularia grisea. Plant Disease. 2002; 86(8):909-914. doi: 10.1094/PDIS.2002.86.8.909

7. Sharma R, Upadhyaya HD, Manjunatha SV, Rai KN, Gupta SK, Thakur RP. Pathogenic variation in the pearl millet blast pathogen, Magnaporthe grisea and identification of resistance to diverse pathotypes. Plant Disease. 2013;97(2):185-195. doi: 10.1094/PDIS-0512-0481-RE

8. Rajan S, Sharma S, Vishal LG. Tapping Pennisetum violaceum, a Wild Relative of Pearl Millet (Pennisetum glaucum), for Resistance to Blast (caused by Magnaporthe grisea) and Rust (caused by Puccinia substriata var. indica). Plant Disease. 2020; 104(5):1487-1491. doi: 10.1094/PDIS-08-19-1602-RE

9. Reddy AA, Rao PP, Yadav OP, et al. Prospects for kharif (Rainy Season)and Summer Pearl Millet in Western India. International Crops Research Institute for the Semi-Arid Tropics, Patancheru, Andhra Pradesh. Working Paper Series no. 2013; 36.

10. DD Serba, RS Yadav, RK Varshney, et al. Genomic Designing of Pearl Millet: A Resilient Crop for Arid and Semi-arid Environments. In: Kole C. (eds) Genomic Designing of Climate-Smart Cereal Crops. Springer, Cham. 2020;221-286. doi: 10.1007/978-3-319-933818_6

11. S Singh, Sharma R, Pushpavathi B, Gupta SK, Durgarani $\mathrm{CV}$, Raj C. Inheritance and allelic relationship among gene(s) for blast resistance in pearl millet [Pennisetum glaucum (L.) R. Br.]. Plant Breed. 2018;137:573- 584. doi: $10.1111 /$ pbr.12607

12. ICRISAT and FAO, The World Sorghum and Millet Economies: Facts, Trends and Outlook, Millets 1996; 1.

13. Thakur RP, Sharma R, Rai KN, Gupta SK, Rao VP. Screening techniques and resistance sources for foliar blast in pearl millet. Journal of SAT Agri Res. 2009; 7:15.

14. Varshney R, Shi C, Thudi M, et al. Pearl millet genome sequence provides a resource to improve agronomic traits in arid environments. Nat Biotechnol. 2017; 35: 969-976. doi: 10.1038/nbt.3943

15. Vasudevan K, Cruz CMV, Gruissem W, Bhullar NK. Large scale germplasm screening for identification of novel rice blast resistance sources. Front Plant Sci., 02, 2014:505. doi: 10.3389/fpls.2014.00505.

16. Wilson JP, Gates RN. Forage yield losses in hybrid pearl millet due to leaf blight caused primarily by Pyricularia grisea. Phytopathology. 1993; 83: 739-743. doi: 10.1094/Phyto-83-739

17. W Knogge. Plant Resistance Genes for Fungal Pathogens - Physiological Models and Identification in Cereal Crops. Z Naturforsch, 46C;1991;969-981. doi: 10.1515/znc-1991-11-1208

18. Srideepthi R, Lakshmisahitya U, Peddakasim D, Suneetha P, Krishna MSR. Morphological, Pathological and Molecular Diversity of Colletotrichum capsici inciting Fruit Rot in Chilli (Capsicum annuum L.). Res. Jour. Biotech. 2017;12(4):14-21

19. Baite M, Sharma RK. Isolation technique and culture conditions of false smut pathogen (Ustilaginoidea virens) on rice. Indian Phytopathology. 2015; 68: 5055.

20. Thakur RP, Sharma R, Rao VP. Screening Techniques for Pearl Millet Diseases. Information Bulletin No. 89. Patancheru 502 324, Andhra Pradesh, India: International Crops Research Institute for the SemiArid Tropics. 2011;56. 